\title{
Occupational risk and chronic kidney disease: a population-based study in the United States adult population
}

\author{
Sofia Rubinstein' \\ Chengwei Wang' \\ Wenchun $\mathrm{Qu}^{2}$ \\ 'Department of Medicine, Nassau \\ University Medical Center, East \\ Meadow, NY, USA; ${ }^{2}$ Department of \\ Physical Medicine and Rehabilitation, \\ Mayo Clinic, Rochester, MN, USA
}

This article was published in the following Dove Press journal: International Journal of Nephrology and Renovascular Disease 8 March 2013

Number of times this article has been viewed

Objective: Previous studies on occupational risk for chronic kidney disease (CKD) have analyzed a limited range of occupations and focused on nephrotoxins. The primary purpose of this study was to examine the relative risk for the occurrence of CKD between different occupations in the US adult population.

Materials and methods: This was a population-based survey study of 91,340 participants in the US, who completed the National Health Interview Survey, 2004 through 2008. The outcome variable, CKD, was defined as having weakening/failing kidneys in the past 12 months, as diagnosed by a physician. The predictor variable, occupation, was obtained using the census occupational codes, regrouped according to North American Industrial Classification System. Results: After controlling for age, gender, hypertension, and education, and with the category Life, Physical, and Social Science Occupations as a reference group, the likelihood of developing CKD was 4.3 times higher in respondents working in Building, Grounds Cleaning and Maintenance Occupations, 4.4 times higher in Healthcare Practitioners and Technical Occupations, 4.7 times higher in Transportation and Material Moving Occupations and in Computer and Mathematical Occupations, 4.8 times higher in Production Occupations, 5.3 times higher in Food Preparation and Serving Related Occupations, and 6.1 times higher in Healthcare Support Occupations and in Legal Occupations.

Conclusion: This study identified occupation groups in US adult population with increased risk for CKD. Alleviation of workplace stress is suggested as a goal for behavioral intervention in high-risk occupations.

Keywords: CKD, risk factors, occupations

\section{Introduction}

Chronic kidney disease (CKD) is a major health problem in the United States. ${ }^{1}$ With a prevalence of $13.1 \%$ and growing, ${ }^{2}$ it is associated with major health care expenditures, totaling \$41 billion in 2010, which accounts for 17\% of the total Medicare spending for the year. ${ }^{3}$ The leading causes of CKD include poorly controlled diabetes, hypertension, chronic glomerulonephritis, and polycystic kidney disease. ${ }^{4}$ Other risk factors include older age, cardiovascular disease, smoking, obesity, hyperlipidemia, chronic urinary tract obstructions, malignancy, and socioeconomic status, ${ }^{2,4-7}$

There has been a significant amount of interest in occupation as a risk factor for $\mathrm{CKD}$, given the size of the associated risk and the fact that occupational factors are uniquely preventable. However, the epidemiological evidence for delineating the complex interactions between occupational risk factors for CKD is scarce. Reports on occupational risk factors have focused on the exposures to nephrotoxins, including lead, 
mercury, glycol ethers, organic solvents, copper, chromium, tin, mercury, welding fumes, silicon-containing compounds, and grain dust. ${ }^{8-11}$ Nevertheless, occupational effect is not limited to nephrotoxins. In fact, individuals at risk are not only those who are in occupations with the highest burden of nephrotoxin exposure. ${ }^{12}$ Lower socioeconomic status appears to be independently associated with increased risk for CKD. ${ }^{6,7,13}$ Additionally, high-stress behaviors have been found to be associated with increased sympathetic activity ${ }^{14}$ that in turn, has been found to be associated with higher risk for initial stage renal disease as well as advanced stage renal failure. ${ }^{15-18}$

The quantitative burden of CKD associated with occupational exposure is unknown. The reported extent of occupational effects on CKD has been suggested to be underestimated. ${ }^{12}$ It was reported that of all occupation-related CKD deaths, about $8.2 \%-14.5 \%$ are attributable to silica, organic solvents, lead, and cadmium exposures. ${ }^{19}$ Occupations such as cashier, sales representative, carpenter, and manager have been found to be associated with the increased mortality risk for CKD. ${ }^{20}$ Job settings in hospitals, eating and drinking places, and construction sites have also been found to be associated with the risk of developing CKD. ${ }^{20}$

It is thus essential to identify specific occupations associated with CKD for the further understanding of the mechanism of how these occupations increase CKD risk. There has not been a population-based study that examines a comprehensive list of occupations in order to identify the high-risk occupations in the United States. Therefore, the purpose of this study was to examine the US general population to identify high-risk occupations for CKD. The working hypothesis was that different types of occupations are associated with a different level of risk of developing CKD.

\section{Materials and methods Study design and subjects}

The National Health Interview Survey ${ }^{21}$ (NHIS) is a nationwide cross-sectional survey, conducted annually by the National Center for Health Statistics, Centers for Disease Control and Prevention (CDC) as in-person interviews, using a complex, multistage sampling design. ${ }^{22}$ It is the principal source of information on the health of the civilian, noninstitutionalized population of the United States. The NHIS has been conducted continuously since its beginning in 1957. In 1988, an occupational health supplement, sponsored jointly by the National Institute for Occupational Safety and Health and the Bureau of Labor Statistics, was added to the core questions. ${ }^{23}$ It was designed to provide
US national prevalence estimates for selected occupational conditions and their risk factors. Detailed descriptions of the data sets have been previously published..$^{24-26}$ The study was approved by the local institutional review committee. During the 5-year period spanning 2004 to 2008, 132,203 adults of the US general population participated in the NHIS survey, of which 91,340 were included in this analysis, based on the following criteria: The first criteria was age between 18 and 70 years. We limited the age of participants to younger or equal to 70 years of age to reflect exposure to occupation. Second, several ethnic groups with smaller numbers of subjects were not included in the final analyses because there were insufficient numbers of subjects to allow examination of ethnic differences in the associations between occupational exposure and risk of CKD. We included all White and Black/African American participants who identified themselves with an occupation as either currently working or ever worked. Lastly, those with cancers were excluded because previous study showed that they had different risk factors for CKD than other workers. ${ }^{27}$

\section{Variables}

As the main outcome measure, CKD was defined as having weakening/failing kidneys in the past 12 months, as diagnosed by a physician. The independent variable was occupation. Using the census occupational codes, regrouped according to the North American Industrial Classification System (NAICS), ${ }^{28}$ occupations were separated into 23 occupational categories: Architecture and Engineering; Arts, Design, Entertainment, Sports and Media; Building and Grounds Cleaning and Maintenance; Community and Social Services; Computer and Mathematical; Construction and Extraction; Education, Training, and Library; Farming, Fishing, and Forestry; Food Preparation and Serving Related; Healthcare Practitioners and Technical; Healthcare Support; Installation, Maintenance, and Repair; Legal; Management; Military Specific; Office and Administrative Support; Personal Care and Service; Production; Protective Service; Sales and Related; Transportation and Material Moving; Business and Financial Operations; and Life, Physical, and Social Science. Each category was coded as an indicator variable. The category Life, Physical, and Social Science was used as the reference group because it had the lowest rate of CKD in past 12 months. Age was grouped into 18-30, 31-40, 41-50, 51-60, and 61-70 years. To provide ethnicity-specific analysis, we restricted our analyses to Whites only $(\mathrm{N}=75,778)$ and Black/African American only $(\mathrm{N}=15,562)$, due to insufficient representation of other races. Data on education, 
income, health insurance coverage, access to health care, coronary heart disease, stroke, cancer, diabetes, smoking status, body mass index (BMI), high cholesterol, lupus, and taking diuretics for any health conditions were also collected as variables.

\section{Statistical analysis}

Demographic characteristics as well as the occupations were assessed by univariate analysis. A base logistic regression model for CKD was developed, using occupation as independent variable and confounders according to the result of the univariate analysis and a step-wise model construction. Inclusion of potential confounders in the models was based on a review of the literature and changes in effect estimates of at least $10 \%$ in a step-up regression. Age, gender, ethnicity, and hypertension status, and education were included. Other potential confounders, including income, need for medical care and not receiving it, health insurance coverage, coronary heart disease, stroke, high cholesterol, diabetes, lupus, BMI (obesity), taking diuretics for any health conditions, and smoking status, did not change the effect of occupation on CKD by more than $10 \%$ and therefore were not included in the analysis. Finally, the number of participants having CKD in past 12 months and all explanatory variables were estimated using the SURVEYFREQ procedure of the SAS statistical package. We also performed logistic regression on the survey weighted data with the SURVEYLOGISTIC procedure of the SAS statistical package, so that the results would truly reflect the percentages in the US population, even though data were taken from a sample. The calculation followed a weight algorithm that was developed based on the comparison of the study population with US census 2000 data. All tests were two-sided at a 5\% significance level. SAS version 9.1.3 (SAS Institute Inc, Cary, NC, USA) was used for all analyses. ${ }^{29}$

\section{Results}

A sample of 91,340 participants were included in this study, of which $53.1 \%$ were females, $83 \%$ were white, $72.3 \%$ had BMI of less than or equal to 30 , and $57.2 \%$ were nonsmokers. Among the study participants, $1.3 \%$ had CKD in the past 12 months. The majority of the subjects had health insurance (94.1\%). Most subjects did not have coronary heart disease (97.2\%), stroke (98.3\%), or diabetes $(92.5 \%)$ (Table 1).

By a univariate analysis, we found that older workers and workers with hypertension had an increased risk for CKD. Among all variables studied, the following occupations were associated with the most increased risks for
CKD: Healthcare Support Occupations, Protective Service Occupations, Food Preparation and Serving Related Occupations, Building and Grounds Cleaning and Maintenance Occupations, Personal Care and Service Occupations, Sales and Related Occupations, Office and Administrative Support Occupations, Farming, Fishing, and Forestry Occupations, Construction and Extraction Occupations, Installation, Maintenance, and Repair Occupations, Production Occupations, and Transportation and Material Moving Occupations. Medical and lifestyle conditions, such as hypertension, coronary heart disease, stroke, diabetes, current everyday smoker, current/ someday smoker, and former smoker, and BMI greater than or equal to $30 \mathrm{~kg} / \mathrm{m}^{2}$ were independently associated with CKD. On the other hand, White race, higher education, and income higher than 20,000 showed protective effect (Table 1).

After applying appropriate weights, controlling for age, gender, hypertension status, and education, and with Life, Physical, and Social Science Occupations as a reference group, respondents were 4.3 times $(95 \%$ confidence interval [CI]: 1.1 to 17.7 ) more likely to develop CKD if they were working in Building and Grounds Cleaning and Maintenance Occupations, 4.4 times (95\% CI: 1.1 to 18.2 ) more likely if they were working in Healthcare Practitioners and Technical Occupations, 4.7 times (95\% CI: 1.2 to 19.0 ) more likely in Transportation and Material Moving Occupations, 4.7 times (95\% CI: 1.1 to 20.7 ) more likely in Computer and Mathematical Occupations, 4.8 times (95\% CI: 1.2 to 19.7 ) more likely in Production Occupations, 5.3 times (95\% CI: 1.3 to 20.8 ) more likely in Food Preparation and Serving Related Occupations, 6.1 times (95\% CI: 1.5 to 25.3 ) more likely in Healthcare Support Occupations, and 6.1 times (95\% CI: 1.2 to 30.3 ) more likely if they were working in Legal Occupations (Table 2).

\section{Discussion}

Using a large, national sample of workers in the United States, after adjusting for age, gender, ethnicity, hypertension status, and education, we found that the following occupational categories were associated with increased risk of CKD: working in Building and Grounds Cleaning and Maintenance Occupations, Healthcare Practitioners and Technical Occupations, Transportation and Material Moving Occupations, Computer and Mathematical Occupations, Production Occupations, Food Preparation and Serving Related Occupations, Healthcare Support Occupations, and Legal Occupations. These results are consistent with a National Mortality Followback Survey study that showed higher mortality secondary to 
Table I Description of risk factors for chronic kidney disease outcome among employed Americans aged I8 to 70 years $(\mathrm{N}=91,340) *$, from the National Health Interview Survey, 2004 to 2008

\begin{tabular}{|c|c|c|c|c|}
\hline Variable & $\mathbf{N}(\%)$ & ${ }^{t} \mathbf{N}(\%)$ of CKD & OR & $\mathrm{Cl}$ \\
\hline Female & $48,485(53.1)$ & $659(1.4)$ & & \\
\hline \multicolumn{5}{|l|}{ Age } \\
\hline $18-30$ & $22,062(25.8)$ & $144(0.7)$ & 1.00 & \\
\hline $31-40$ & $|8,32|(21.4)$ & $160(0.9)$ & 1.34 & $1.07,1.68$ \\
\hline $4 I-50$ & $18,724(2 \mid .9)$ & $236(1.3)$ & 1.94 & $1.58,2.39$ \\
\hline $51-60$ & $15,546(18.2)$ & $275(1.8)$ & 2.74 & $2.24,3.36$ \\
\hline $6 I-70$ & $10,816(12.7)$ & $291(2.7)$ & 4.21 & $3.44,5.15$ \\
\hline \multicolumn{5}{|l|}{ Occupation } \\
\hline Life, Physical, and Social Science Occupations & $786(0.9)$ & $2(0.3)$ & 1.00 & \\
\hline Management Occupations & $7311(8)$ & $66(0.9)$ & 3.57 & $0.87,14.6$ \\
\hline Healthcare Practitioners and Technical Occupations & $4|3|(4.5)$ & $40(1.0)$ & 3.83 & $0.92,15.9$ \\
\hline Healthcare Support Occupations & $2592(2.8)$ & $58(2.2)$ & 8.97 & $2.19,36.8$ \\
\hline Protective Service Occupations & $1794(2)$ & $22(1.2)$ & 4.86 & I.I4, 20.7 \\
\hline Food Preparation and Serving Related Occupations & $5063(5.5)$ & $91(1.8)$ & 7.17 & $1.76,29.2$ \\
\hline Building and Grounds Cleaning and Maintenance Occupations & $4476(4.9)$ & $98(2.2)$ & 8.77 & $2.16,35.6$ \\
\hline Personal Care and Service Occupations & $3084(3.4)$ & $51(1.7)$ & 6.59 & I.6, 27.I \\
\hline Sales and Related Occupations & $9640(10.6)$ & $118(1.2)$ & 4.86 & $1.2,19.7$ \\
\hline Office and Administrative Support Occupations & $13,297(\mid 4.6)$ & $14 \mid(1.1)$ & 4.20 & $1.04,17$ \\
\hline Farming, Fishing, and Forestry Occupations & $836(0.9)$ & $16(1.9)$ & 7.64 & $1.75,33.3$ \\
\hline Construction and Extraction Occupations & $5649(6.2)$ & $59(1.0)$ & 4.14 & I.01, 17 \\
\hline Business and Financial Operations Occupations & $3511(3.8)$ & $35(1.0)$ & 3.95 & $0.95,16.4$ \\
\hline Installation, Maintenance, and Repair Occupations & $3036(3.3)$ & $35(1.2)$ & 4.57 & $1.1,19$ \\
\hline Production Occupations & $7423(8.1)$ & $142(1.9)$ & 7.64 & $1.89,30.9$ \\
\hline Transportation and Material Moving Occupations & $5690(6.2)$ & $114(2.0)$ & 8.01 & $1.98,32.5$ \\
\hline Military Specific Occupations & $222(0.2)$ & $\mathrm{I}(0.5)$ & 1.77 & $0.16,19.6$ \\
\hline Computer and Mathematical Occupations & $1773(1.9)$ & $16(0.9)$ & 3.57 & $0.82,15.5$ \\
\hline Architecture and Engineering Occupations & $1404(1.5)$ & $12(0.9)$ & 3.38 & $0.75,15.1$ \\
\hline Community and Social Services Occupations & $14,80(1.6)$ & II (0.7) & 2.93 & $0.65,13.3$ \\
\hline Legal Occupations & $897(1)$ & $8(0.9)$ & 3.53 & $0.75,16.6$ \\
\hline Education, Training, and Library Occupations & $5576(6.1)$ & $5 I(0.9)$ & 3.62 & $0.88,14.9$ \\
\hline Arts, Design, Entertainment, Sports and Media Occupations & $1669(1.8)$ & $10(0.6)$ & 2.36 & $0.52,10.8$ \\
\hline Hypertension & $18370(20.1)$ & $705(3.8)$ & 5.94 & $5.29,6.68$ \\
\hline \multicolumn{5}{|l|}{ Race } \\
\hline White & $75,778(83)$ & $891(1.2)$ & 0.59 & $0.52,0.68$ \\
\hline Black/African American & $15,562(17)$ & $306(2.0)$ & 1.00 & \\
\hline \multicolumn{5}{|l|}{ Education } \\
\hline Did not finish high school & $16,635(18.3)$ & $406(2.4)$ & 1.00 & \\
\hline Completed high school & $22,635(24.9)$ & $302(1.3)$ & 0.54 & $0.46,0.63$ \\
\hline Some college or technical school & $28,212(31)$ & $322(1.1)$ & 0.46 & $0.4,0.53$ \\
\hline Completed college & $15,685(17.3)$ & III (0.7) & 0.28 & $0.23,0.35$ \\
\hline Some graduate training after college & $7737(8.5)$ & $48(0.6)$ & 0.25 & $0.18,0.34$ \\
\hline \multicolumn{5}{|l|}{ Total earnings last year } \\
\hline$\$ 01-\$ 4,999$ & $4406(7.5)$ & $61(1.4)$ & 1.00 & \\
\hline$\$ 5,000-\$ 9,999$ & $4229(7.2)$ & $49(1.2)$ & 0.83 & $0.57,1.22$ \\
\hline$\$ 10,000-\$ 14,999$ & $5350(9.1)$ & $64(1.2)$ & 0.86 & $0.61,1.23$ \\
\hline$\$ 15,000-\$ 19,999$ & $5068(8.6)$ & $56(I . I)$ & 0.80 & $0.55,1.15$ \\
\hline$\$ 20,000-\$ 24,999$ & $5728(9.7)$ & $42(0.7)$ & 0.53 & $0.35,0.78$ \\
\hline$\$ 25,000-\$ 34,999$ & $967 \mid(16.5)$ & $62(0.6)$ & 0.46 & $0.32,0.66$ \\
\hline$\$ 35,000-\$ 44,999$ & $7730(13.2)$ & $50(0.7)$ & 0.46 & $0.32,0.68$ \\
\hline$\$ 45,000-\$ 54,999$ & $5489(9.3)$ & $33(0.6)$ & 0.43 & $0.28,0.66$ \\
\hline$\$ 55,000-\$ 64,999$ & $3340(5.7)$ & $14(0.4)$ & 0.30 & $0.17,0.54$ \\
\hline$\$ 65,000-\$ 74,999$ & $2238(3.8)$ & $10(0.5)$ & 0.32 & $0.16,0.63$ \\
\hline$\$ 75,000$ and over & $5512(9.4)$ & $25(0.5)$ & 0.32 & $0.2,0.52$ \\
\hline Ever been told you had coronary heart disease & $2534(2.8)$ & $200(7.9)$ & 7.63 & $6.52,8.93$ \\
\hline Ever been told you had a stroke & $1512(1.7)$ & $134(8.9)$ & 8.14 & 6.759 .82 \\
\hline
\end{tabular}


Table I (Continued)

\begin{tabular}{|c|c|c|c|c|}
\hline Variable & 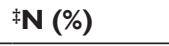 & ${ }^{t} \mathbf{N}(\%)$ of CKD & OR & $\mathrm{Cl}$ \\
\hline \multicolumn{5}{|l|}{ Ever told you have diabetes } \\
\hline No & $84,462(92.5)$ & $770(0.9)$ & 1.00 & \\
\hline Borderline & $820(0.9)$ & $33(4.0)$ & 4.56 & $3.19,6.5$ \\
\hline Yes & $6024(6.6)$ & $392(6.5)$ & 7.57 & $6.68,8.57$ \\
\hline \multicolumn{5}{|l|}{ Smoking status } \\
\hline Never smoker & $51,846(57.2)$ & $558(\mathrm{I} . \mathrm{I})$ & 1.00 & \\
\hline Current every day smoker & $16,7 \mid 7(18.4)$ & $265(1.6)$ & 1.48 & I.28, I.72 \\
\hline Current someday smoker & $4556(5)$ & $70(1.5)$ & 1.43 & I.I2, I.84 \\
\hline Former smoker & $17,508(19.3)$ & $293(1.7)$ & 1.56 & $1.36,1.8$ \\
\hline \multicolumn{5}{|l|}{ BMI } \\
\hline $\mathrm{BMI}<30$ & $63,545(72.3)$ & $714(1.1)$ & 1.00 & \\
\hline $40>\mathrm{BMI} \geq 30$ & $20,733(23.6)$ & $346(1.7)$ & 1.49 & I.31, I.7 \\
\hline $\mathrm{BMI} \geq 40$ & $3659(4.2)$ & $93(2.5)$ & 2.30 & $\mathrm{I} .85,2.86$ \\
\hline Chronic kidney disease & $1197(1.3)$ & $1197(100)$ & & \\
\hline
\end{tabular}

Notes: *Cases were defined as subjects with physician-diagnosed weak/failing kidneys in the past 12 months, whereas control subjects had no weak/failing kidneys in the past 12 months. All variables except sex and chronic kidney disease were statistically significant different between two ethnicity groups, $P$-value $<0.05$. ${ }^{\ddagger}$ Number of subjects (percent of total). ${ }^{\mathrm{N}}$ Number of subjects with weak/failing kidneys in past 12 months (percent of number of subjects). Numbers might not add up due to missing values. Percentages are reported among nonmissing observations.

Abbreviations: CKD, chronic kidney disease; OR, odds ratio; $\mathrm{Cl}$, confidence ratio.

occupation-associated renal failure, where those at high risk were found to be workers in construction, eating/drinking places, hospitals, and agriculture, and household cleaners/ servants. ${ }^{20}$ Contrary to the prevalent belief that occupational risks of CKD are due to exposure to nephrotoxins (as implied by the fact that most of the studies have focused on nephrotoxins), our findings showed that the highest-risk occupations for CKD are not necessarily, nor mainly, associated with exposures to nephrotoxins. In addition, the extent of occupation- and environment-associated CKD also supports the viewpoint that goes beyond nephrotoxins exposure. It has been estimated that at least $50 \%$ of patients with CKD had renal diseases due to occupational or environmental factors. ${ }^{30}$ Although there is no accurate estimate of the prevalence of occupational nephrotoxin exposure at disease-causing level, it would be far short of affecting half of all patients with CKD. The cause for those occupation-related CKD nonattributable to toxins would require examination of the psychosocial risk factors that are inherent with certain occupations. In this study, the occupations identified as associated with higher risk of CKD are those associated with potential workplace stressors, including job strain, noise, or shift work, all of which were found to increase the sympathetic activity in the workers. ${ }^{14}$

Newly developed techniques of sympathetic-activity assessment using microneurographic recording of efferent postganglionic sympathetic nerve traffic has made possible the evaluation of the role of sympathetic activity in the development of CKD. ${ }^{15-18}$ Sympathetic activation has been found to be associated with early clinical phases of the renal alteration as well as late clinical stages of renal failure. . $^{16,17}$ Subsequently, sympathetic deactivation has been proposed to be a target for pharmacological intervention in severe as well as in mild forms of CKD. ${ }^{16}$ Similarly, from the perspective of behavioral intervention, we propose that alleviation of workplace stressors should be a goal in prevention of $\mathrm{CKD}$, particularly in the high-risk occupations identified herewith.

The strength of this study lies in the nationally representative, large sample size that allows for investigation of risk factors for uncommon conditions. However, there are several limitations in this study. First, this was a crosssectional study, therefore, the sequence of events and length of occupation before the development of CKD could not be determined. Second, CKD was self-reported as a weak/ failing kidney diagnosed by a physician. It is possible that some patients mismatched their physicians' impression with the presence of CKD. Some might not have remembered, while others, particularly in the presence of mild forms of CKD, might not have been told. However, the extent of this mismatch should be limited: even though we were not able to obtain the laboratory evidence of $\mathrm{CKD}$, the fact that the questionnaire asked specifically for a diagnosis that had been made by a physician provided reasonable assurance in preventing recall bias. Third, the categories of occupation were broadly-defined, making it difficult to extrapolate more detailed implications regarding occupation-specific risk factors, such as work-related stress, ability to have rest time, 
Table 2 The association between occupation and weak/failing kidneys in the past 12 months, with weight given to underrepresented populations*,\$ll

\begin{tabular}{|c|c|c|c|}
\hline Occupation & OR & ${ }^{\ddagger} \mathbf{C l}$ & ${ }^{\dagger} \operatorname{Pr}>$ Chi-Square \\
\hline Military Specific Occupations & 0.93 & $0.09,10.2$ & 0.9539 \\
\hline Installation, Maintenance, and Repair Occupations & 2.54 & $0.6,10.7$ & 0.2047 \\
\hline Community and Social Services Occupations & 2.85 & $0.62,13$ & 0.1770 \\
\hline Architecture and Engineering Occupations & 2.92 & $0.64,13.3$ & 0.1661 \\
\hline Arts, Design, Entertainment, Sports and Media Occupations & 3.26 & $0.7 I, 15$ & 0.1292 \\
\hline Office and Administrative Support Occupations & 3.28 & $0.8,13.5$ & 0.1002 \\
\hline Protective Service Occupations & 3.34 & $0.9,12.4$ & 0.0711 \\
\hline Construction and Extraction Occupations & 3.39 & $0.85,13.6$ & 0.0849 \\
\hline Business and Financial Operations Occupations & 3.47 & $0.83,14.4$ & 0.0877 \\
\hline Management Occupations & 3.51 & $0.86,14.2$ & 0.0792 \\
\hline Farming, Fishing, and Forestry Occupations & 3.59 & $0.78,16.5$ & 0.1003 \\
\hline Sales and Related Occupations & 3.88 & $0.99,15.2$ & 0.0522 \\
\hline Education, Training, and Library Occupations & 3.96 & $0.97,16.1$ & 0.0550 \\
\hline Personal Care and Service Occupations & 3.98 & $0.99,16$ & 0.0519 \\
\hline Building and Grounds Cleaning and Maintenance Occupations & 4.32 & $1.06,17.7$ & 0.0415 \\
\hline Healthcare Practitioners and Technical Occupations & 4.38 & $1.05,18.2$ & 0.0420 \\
\hline Transportation and Material Moving Occupations & 4.72 & $1.17,19.0$ & 0.0290 \\
\hline Computer and Mathematical Occupations & 4.74 & $\mathrm{I} .08,20.7$ & 0.0389 \\
\hline Production Occupations & 4.79 & I.17, 19.7 & 0.0297 \\
\hline Food Preparation and Serving Related Occupations & 5.29 & I.34, 20.8 & 0.0172 \\
\hline Healthcare Support Occupations & 6.08 & $1.46,25.3$ & 0.0131 \\
\hline Legal Occupations & 6.14 & $1.24,30.3$ & 0.0258 \\
\hline
\end{tabular}

Notes: *Models were adjusted for age, sex, ethnicity, hypertension status, and education. Cases were defined as subjects with physician-diagnosed weak/failing kidneys in the past 12 months, whereas control subjects had no weak/failing kidneys in the past 12 months. ${ }^{\S}$ The table is ordered by odds ratio. There were 5660 observations with cancer that were removed from the total 97,000 observations. "The rates were weighted to reflect the percentage in the US population, despite being taken from a sample. Consideration was taken and weight given to underrepresented populations. The calculation followed an algorithm that was developed based on the comparison of the study population with US census 2000 data. $\$ 95 \%$ Wald confidence interval. Reference group: Life, Physical, and Social Science occupations (because it had the lowest rate of weak/ failing kidneys in the past 12 months). ${ }^{\dagger}$ Chi-square probability was calculated from maximum likelihood estimation.

Abbreviations: $\mathrm{OR}$, odds ratio; $\mathrm{Cl}$, confidence interval.

and access to fluids. Lastly, the self-report data cannot be independently validated.

In summary, the main findings of our study are as follow. There was an increased risk for CKD in the categories of Healthcare Support Occupations, Protective Service Occupations, Food Preparation and Serving Related Occupations, Building and Grounds Cleaning and Maintenance Occupations, Personal Care and Service Occupations, Sales and Related Occupations, Office and Administrative Support Occupations, Farming, Fishing, and Forestry Occupations, Construction and Extraction Occupations, Business and Financial Operations Occupations, Installation, Maintenance, and Repair Occupations, Production Occupations, and Transportation and Material Moving Occupations. Since the prevalence of CKD is high and occupation-related causes are, in general, preventable, it would be beneficial to offer interventions to the occupationally susceptible groups, with a goal of decreasing the workplace stress in order to delay the onset of CKD or to prevent CKD completely. The findings of this study also warrant further, more detailed investigations into non-nephrotoxin-related factors, such as psychosocial risk factors, that are inherent in certain occupations.

\section{Acknowledgments}

The authors would like to thank Alan Multz, MD and Leah Balsam, MD from the Nassau University Medical Center, NY for their invaluable comments and help with this manuscript.

\section{Disclosure}

The authors report no conflicts of interest in this work.

\section{References}

1. Coresh J, Stevens LA, Levey AS. Chronic kidney disease is common: what do we do next? Nephrol Dial Transplant. 2008;23(4):1122-1125.

2. Coresh J, Selvin E, Stevens LA, et al. Prevalence of chronic kidney disease in the United States. JAMA. 2007;298(17):2038-2047.

3. US Renal Data System. USRDS 2008 Annual Data Report: Atlas of Chronic Kidney Disease and End-Stage Renal Disease in the United States. Bethesda: US Renal Data System; 2008. Available from: http:// www.usrds.org/2008/view/default.asp. Accessed January 17, 2013.

4. US Renal Data System. USRDS 2012 Annual Data Report: Atlas of End-stage Renal Disease in the United States. Bethesda: US Renal Data System; 2012. Available from: http://www.usrds.org/adr.aspx. Accessed January 17, 2013.

5. Foley RN, Collins AJ. End-stage renal disease in the United States: an update from the United States Renal Data System. J Am Soc Nephrol. 2007;18(10):2644-2648.

6. Fored CM, Ejerblad E, Fryzek JP, et al. Socio-economic status and chronic renal failure: a population-based case-control study in Sweden. Nephrol Dial Transplant. 2003;18(1):82-88. 
7. Merkin SS, Diez Roux AV, Coresh J, Fried LF, Jackson SA, Powe NR. Individual and neighborhood socioeconomic status and progressive chronic kidney disease in an elderly population: The Cardiovascular Health Study. Soc Sci Med. 2007;65(4):809-821.

8. Landrigan PJ, Goyer RA, Clarkson TW, et al. The work-relatedness of renal disease. Arch Environ Health. 1984;39(3):225-230.

9. Nuyts GD, Van Vlem E, Thys J, et al. New occupational risk factors for chronic renal failure. Lancet. 1995;346(8966):7-11.

10. Rhoads CS, Daniell WE. Renal and bladder disorders. In: Rosenstock L, Cullen MR, Brodkin CA, Redlich CA, editors. Textbook of Clinical Occupational and Environmental Medicine, 2nd ed. Philadelphia: Elsevier Health Sciences; 2005:565-586. Available at: http://www. sciencedirect.com/science/article/pii/B9780721689746500294.

11. Stengel B, Cénée S, Limasset JC, et al. Organic solvent exposure may increase the risk of glomerular nephropathies with chronic renal failure. Int J Epidemiol. 1995;24(2):427-434.

12. Dieperink HH. Identification of groups at risk for renal diseases (including nephrotoxicity). Toxicol Lett. 1989;46(1-3):257-268.

13. Jennette CE, Vupputuri S, Hogan SL, Shoham DA, Falk RJ, Harward DH. Community perspectives on kidney disease and health promotion from at-risk populations in rural North Carolina, USA. Rural Remote Health. 2010;10(2):1388.

14. van Amelsvoort LG, Schouten EG, Maan AC, Swenne CA, Kok FJ. Occupational determinants of heart rate variability. Int Arch Occup Environ Health. 2000;73(4):255-262.

15. Grassi G, Bertoli S, Seravalle G. Sympathetic nervous system: role in hypertension and in chronic kidney disease. Curr Opin Nephrol Hypertens. 2012;21(1):46-51.

16. Grassi G, Quarti-Trevano F, Seravalle G, et al. Early sympathetic activation in the initial clinical stages of chronic renal failure. Hypertension. 2011;57(4):846-851.

17. Grassi G, Seravalle G, Arenare F, et al. Behaviour of regional adrenergic outflow in mild-to-moderate renal failure. J Hypertens. 2009;27(3): $562-566$.

18. Schlaich MP. Sympathetic activation in chronic kidney disease: out of the shadow. Hypertension. 2011;57(4):683-685.

19. Steenland K, Burnett C, Lalich N, Ward E, Hurrell J. Dying for work: The magnitude of US mortality from selected causes of death associated with occupation. Am J Ind Med. 2003;43(5):461-482.

20. Reviere R, Schneider S, Woolbright K. Associations between disease and occupation: hypotheses generated from the National Mortality Followback Survey. Am J Ind Med. 1995;27(2):195-205.
21. National Center for Health Statistics. Data file documentation. National Health Interview Survey, 2009 (machine readable data file and documentation). Hyattsville: National Center for Health Statistics, Centers for Disease Control and Prevention; 2009.

22. Botman SL, Moore TF, Moriarity CL, Parsons VL. Design and Estimation for the National Health Interview Survey, 1995-2004. Hyattsville: National Center for Health Statistics. Vital Health Stat; 2000;2(130). Available from: http://www.cdc.gov/nchs/data/series/sr_02/sr02_130. pdf. Accessed January 17, 2013.

23. Tanaka S, Wild DK, Cameron LL, Freund E. Association of occupational and non-occupational risk factors with the prevalence of selfreported carpal tunnel syndrome in a national survey of the working population. Am J Ind Med. 1997;32(5):550-556.

24. Massey JT, Moore TF, Parsons VL, Tadros W. Design and Estimation for the National Health Interview Survey, 1985-1994. Hyattsville: National Center for Health Statistics. Vital Health Stat; 1989;2(110). Available from: http://www.cdc.gov/nchs/data/series/sr_02/sr02_110. pdf. Accessed January 17, 2013.

25. Park CH, Wagener DK, Winn DM, Pierce JP. Health Conditions Among the Currently Employed. Hyattsville: National Center for Health Statistics. Vital Health Stat; 1993;10(186). Available from: http://www.cdc.gov/ nchs/data/series/sr_10/sr10_186.pdf. Accessed January 17, 2013.

26. Tanaka S, Wild DK, Seligman PJ, Halperin WE, Behrens VJ, Putz-Anderson V. Prevalence and work-relatedness of self-reported carpal tunnel syndrome among U.S. workers: analysis of the Occupational Health Supplement data of 1988 National Health Interview Survey. Am J Ind Med. 1995;27(4):451-470.

27. Faria TV, Baptista MA, Burdmann EA, Cury PM. Renal glomerular alterations in patients with cancer: a clinical and immunohistochemical autopsy study. Ren Fail. 2010;32(8):918-922.

28. census.gov [homepage on the Internet]. North American Industry Classification System. US Census Bureau; 2000 [updated October 25, 2012; cited September 3, 2011]. Available from: http://www.census.gov/ cgi-bin/sssd/naics/naicsrch?chart=2012. Accessed January 18, 2013.

29. Nutter RD, Thomas RW. An analysis of psychiatric patient attributes in Salford using categorical data models. Soc Sci Med. 1990;30(1): 83-94.

30. Simon P. Chronic renal failure: are there environmental and occupational risk factors? Toxin Review. 1999;18(3-4):313-321.

\section{Publish your work in this journal}

The International Journal of Nephrology and Renovascular Disease is an international, peer-reviewed open-access journal focusing on the pathophysiology of the kidney and vascular supply. Epidemiology, screening, diagnosis, and treatment interventions are covered as well as basic science, biochemical and immunological studies. The journal welcomes original research, clinical studies, reviews \& evaluations, expert opinion and commentary, case reports and extended reports. The manuscript management system is completely online and includes a very quick and fair peerreview system, which is all easy to use. Visit http://www.dovepress.com/ testimonials.php to read real quotes from published authors. 